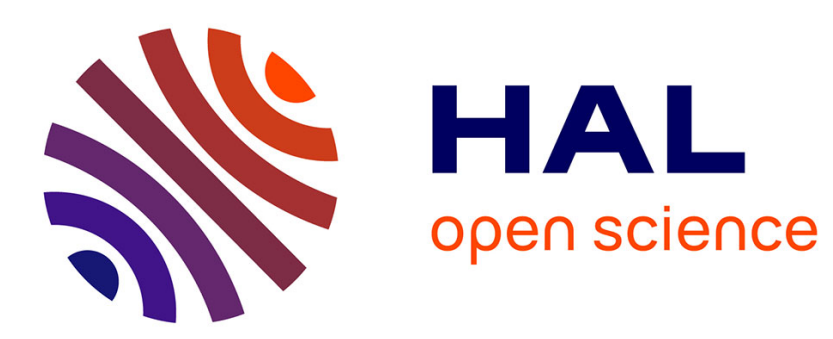

\title{
Separation of particles from syngas at high-temperatures with an electrostatic precipitator
}

Audrey Villot, Yves Gonthier, Evelyne Gonze, Alain Bernis, Serge Ravel, Maguelone Grateau, Jacques Guillaudeau

\section{To cite this version:}

Audrey Villot, Yves Gonthier, Evelyne Gonze, Alain Bernis, Serge Ravel, et al.. Separation of particles from syngas at high-temperatures with an electrostatic precipitator. Separation and Purification Technology, 2012, 92, pp.181 - 190. 10.1016/j.seppur.2011.04.028 . hal-01779461

\section{HAL Id: hal-01779461 \\ https://hal.science/hal-01779461}

Submitted on 13 Jun 2018

HAL is a multi-disciplinary open access archive for the deposit and dissemination of scientific research documents, whether they are published or not. The documents may come from teaching and research institutions in France or abroad, or from public or private research centers.
L'archive ouverte pluridisciplinaire HAL, est destinée au dépôt et à la diffusion de documents scientifiques de niveau recherche, publiés ou non, émanant des établissements d'enseignement et de recherche français ou étrangers, des laboratoires publics ou privés. 


\section{Elsevier Editorial System(tm) for Separation and Purification Technology Manuscript Draft}

Manuscript Number:

Title: Separation of particles from syngas at high-temperatures with an electrostatic precipitator

Article Type: Special Issue: FPS 2010

Corresponding Author: Mrs Audrey Villot, Ph.D

Corresponding Author's Institution: Locie FRE CNRS 3220-Savoie University

First Author: Audrey Villot, Ph.D

Order of Authors: Audrey Villot, Ph.D; Yves Gonthier, Professor; Evelyne Gonze, Professor; Alain Bernis, Professor; Serge Ravel; Maguelone Grateau; Jacques Guillaudeau

Manuscript Region of Origin: FRANCE 
Corresponding aurhor : Audrey Villot

Tel : +33(0) 479759418

Fax : +33 (0) 479758144

e-mail : audrey.villot@univ-savoie.fr

adresse : LOCIE CNRS FRE 3220

Université de Savoie - Polytech'Savoie

73376 Le Bourget du Lac - CEDEX - France

December 22, 2010

Dear Madam, Sir,

The study, which is submit to you, was supported by the French National Agency and it is incorporated in the EPURGAZ project (ANR-06-BIOE-O05). The aim of this project was to study the different existing possible way to clean syngas from biomass gasification at high temperatures $\left(>500^{\circ} \mathrm{C}\right.$ ). This project was realized in partnership with the French Institute of Petrol (IFP - Lyon), the French Atomic Energy Commission (CEA - Grenoble), Air Liquid (Loges en Josas) and the Savoie University.

This study shown the possibility to use an electrostatic precipitator at temperatures above $500^{\circ} \mathrm{C}$ to remove the particles contained in syngas from biomass gasification. Indeed, the filtration efficiency obtained during the filtration tests conducted at the CEA site in Grenoble, FRANCE, were greater than $95 \%$.

I submit you only 2 reviewers because I did not find an others :

Dominique THOMAS

Laboratoire Réactions et Génie des Procédés UPR3349 CNRS, Groupe SAFE

1 rue Grandville

BP 20451 - 54001 Nancy Cedex, France

Tel: +33 (0) 383175197 / dominique.thomas@ensic.inpl-nancy.fr

Wilhelm Hoflinger

Vienna University of Technology

Institute of Chemical Engineering

Mechanical Process Engineering and Clean Air technology

Vienna, Austria

Tel: +43 (1) 5880115910 / Wilhelm.hoeflinger@tuwien.ac.at

Yours sincerely

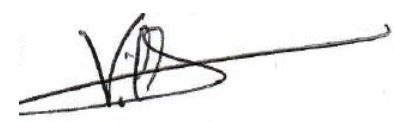

Villot Audrey 
- The possibility of removing the particles from syngas at high temperature with an electrostatic precipitator $\left(>500^{\circ} \mathrm{C}\right)$ was studied.

- Syngas filtration tests conducted directly downstream of a gasifier.

- Two filtration tests were realized : the first at a temperature of $510^{\circ} \mathrm{C}$ and the second at $680^{\circ} \mathrm{C}$.

- For each filtration tests, an average mass filtration efficiency greater than $95 \%$ was obtained. 


\title{
Separation of Particles from Syngas at High- Temperatures with an Electrostatic Precipitator
}

\author{
Audrey Villot*a ${ }^{*}$, Yves Gonthier ${ }^{\mathrm{a}}$, Evelyne Gonze ${ }^{\mathrm{a}}$, Alain Bernis ${ }^{\mathrm{a}}$, Serge Ravel ${ }^{\mathrm{b}}$, Maguelone Grateau ${ }^{\mathrm{b}}$, \\ Jacques Guillaudeau ${ }^{\mathrm{b}}$ \\ *audrey.villot@univ-savoie.fr \\ ${ }^{a}$ LOCIE FRE CNRS 3220-Université de Savoie, Campus scientifique-Savoie Technolac, 73376 Le Bourget du \\ Lac Cedex, France \\ ${ }^{\mathrm{b}}$ CEA/DRT/LIEN/DTBH/LTB, Laboratoire des technologies de la biomasse, 17 rue des Martyrs, 38054 \\ Grenoble Cedex 9, FRANCE
}

\begin{abstract}
The synthesis gas stemming from biomass gasification contains particles (ashes, soot, etc.), which, if not removed, can induce severe operational damage. The problem is more serious if syngas must be used for chemical synthesis as in the Fischer-Tropsch catalyst reaction or the water-gas shift. The particles contained in syngas can reduce or inhibit the catalyst effect. Moreover, for energy reasons, it is also necessary to develop a filtration process at as high a temperature as possible. To address this issue, a study to show the possibility of removing the particles from syngas with an electrostatic precipitator at high temperature $\left(500-1000^{\circ} \mathrm{C}\right)$ and pressure $(0.1-1 \mathrm{MPa})$ was conducted. Syngas filtration tests conducted directly downstream of a gasifier demonstrated the feasibility of implementing an electrostatic precipitator to clean syngas at temperatures above $500^{\circ} \mathrm{C}$.
\end{abstract}

Index Terms - biofuel, electrostatic precipitator, hot gas cleaning, biomass gasification, syngas 


\section{INTRODUCTION}

The increasing global energy demand, the depletion of fossil fuel resources and the increasing awareness of the environmental risks related to emissions of greenhouse gases have led to a growing interest in biomass energy. In this context, biomass is potentially one of the most profuse renewable energy sources and the only one able to provide for transportation fuel needs. Among the projected technologies for biofuel production, in particular second generation biofuels, thermochemical conversion of biomass has been identified as one of the most promising. In principle, several configurations for the conversion of biomass to a Fischer-Tropsch liquid are possible depending on the gasifier types, the Fischer-Tropsch process and the gas cleaning technology. Figure 1 illustrates of the main steps in the process of converting biomass into synthetic liquid fuel via the Fischer Tropsch process.

The syngas produced by biomass gasification contains numerous contaminants such as particles, tars, sulfur, nitrogen, chlorine compounds, alkali and heavy metals, which, if not removed, can induce severe operational problems. The nature of these contaminants depends on the gasification process and the type of biomass feedstock [1-6]. The need for cleaning syngas depends on how this gas is used, it is particularly important when syngas will be converted to liquid synthetic fuel. Indeed, the catalyst used in the water gas shift or FischerTropsch process are very sensitive to contaminants that may be contained in raw syngas and thus inhibit their effect. Table 1 gives the required specifications by the Fischer-Tropsch process catalyst.

The success of the biomass energy system mainly depends on the performance of the ancillary equipment [7], especially biomass feeding systems and devices to reduce gaseous and particle contaminants from the producer gas. These two steps account for more than half of the final price of produced biofuel $[7,9,10]$. It was demonstrated that cleaning gas at high temperatures would increase the overall efficiency of the system $[1,7,8$, 11]. It is for this reason that hot gas cleaning and tar reduction has been the focus of much research in the last few years.

The objective of this study was to demonstrate the feasibility of removing the particles contained in syngas from high-temperature biomass gasification with an electrostatic precipitator. Particles come from ashes, char, bed material and condensing compounds. They can cause erosion of metallic components and particle deposit formation, they can also decrease the overall efficiency of the process.

\section{PREVIOUS STUDIES}

Two distinct methods of gas cleaning are considered $[1,2,7,8,11]$ :

* Wet low-temperature syngas cleaning is the preferred technology in the short term. The processes currently used in industry such as cyclones, wet electrostatic precipitators, scrubbers, fabric filters, sand bed filters and beds packed with sorbents [2, 7, 12-15] are well under control. These technologies are known as "wet" processes because the condensable substances, which are in gaseous form at high temperatures, are found in liquid form at room temperature. Therefore, waste water sludge is produced, which must be considered a hazardous material due to the presence of tars and must be treated before discarding in the environment. In any case, it is not advisable to cool the syngas to purify it and reheat it to produce biofuels via the Fischer-Tropsch process, which takes place at a temperature between 200 and $400^{\circ} \mathrm{C}$ and a pressure between 2 and $3 \mathrm{MPa}$ depending on the catalyst used [16]. In this configuration the overall energy efficiency is low and gas conditioning is expensive $[1,11,13,17]$.

* Dry high-temperature syngas cleaning, which is still in the research stage, is preferable in the long term. Several economic studies, whose objective was to determine the viability of the conversion of biomass to the Fischer-Tropsch process, demonstrated that cleaning the gas at high temperatures could improve energy efficiency and reduce production costs $[11,12]$. The best solution would be to clean the gas at a temperature between 500 and $1000^{\circ} \mathrm{C}$, with perhaps a preference for a process temperature around $800^{\circ} \mathrm{C}$ [8], which provides the most effective heat recovery of the syngas. Concerning atmospheric gasification, hot gas cleaning does not improve efficiency, as the subsequent compression requires 
syngas cooling [1]. Currently, there is no industrial technology available for gas cleaning at high temperatures to meet the requirements of the Fischer-Tropsch process (Table 1). Further developments are needed. Several high-temperature cleaning processes are described below.

\subsection{Cyclones}

The cyclone is one of the most widely used dust separation technologies in industry. Inexpensive in terms of investment and with low operation costs, it allows continuous operation without accumulation of particles. The cyclone is the first technology that was used to remove particles contained in hot gas, especially coal combustion gases. It has been tested for temperatures up to $900-925^{\circ} \mathrm{C}$ and pressures up to $1-2 \mathrm{MPa}$. Although the pressure impact on the cyclone efficiency is neglected, at high temperatures the viscosity of the gas is increased and the cyclonic effect is reduced, causing loss of efficiency [18].

A major drawback of this technology is the cyclone's ineffectiveness stopping particles smaller than $5 \mu \mathrm{m}$, which can degrade the processes placed downstream of the gasifier. The cyclone can only be considered a pretreatment and be used upstream of a technology able to remove small particles $(<5 \mu \mathrm{m})$. In the biomass gasification pilot units using a cyclone, it was coupled with either a ceramic candle filter [19] or a sintered metal filter [20], providing particle filtration efficiency close to $100 \%$.

\subsection{Candle filters}

Ceramic filters consist of arrays of candle-shaped elements that are made of ceramic or special metal to allow cleaning hot gas.

The ceramic filters currently available are made of a thin outer layer, usually consisting of fine-ground silicon carbide or aluminosilicate, surrounding the main body, which is composed of course-ground silicon carbide. The ceramic filters show very good filtration efficiency, near $100 \%$ for temperatures up to $800^{\circ} \mathrm{C}[7,19,21]$. Unfortunately, this technology has several weaknesses that affect the reliability of its performance:

* Cracks can appear after thermal shock, which occurs mainly during the filter cleaning phase by passing at counter-current of clean gas. One of the solutions to this problem is to use a hot gas to unclog the filters [19].

* Cracks can also appear after explosions inside the candles due to the simultaneous presence of dust and flammable gas $[21,22]$.

* Over time, a residual particle deposit forms on the filter surface and leads to irreversible fouling [13, 21].

To solve the problem of ceramic filter reliability, metal filters have now appeared with the very good filtration efficiency of ceramic filters. Depending on the alloy used in the candles, they can be operated at temperatures up to $1000^{\circ} \mathrm{C}$. However, temperatures reported in the literature are between 400 and $700^{\circ} \mathrm{C}$ [7, 20, 22]. Metal filters like ceramic filters form a residual particle deposit. With the metal filter, this particle deposit can be completely removed by a backwash filter with sulfuric acid [22]. The disadvantage of this method is that it must be carried out at room temperature and requires treating the liquid effluent. Another option discussed by Ghidossi et al. [22] consists in placing the clogged filter in an oven with air circulation at $900^{\circ} \mathrm{C}$ for a predetermined period $(8 \mathrm{~h})$ to allow complete oxidation of the particles leading to their elimination. This method is long and only partially regenerates the filter (approximately $80 \%$ ).

\subsection{Granular bed filters}

Granular bed filters can be an alternative to ceramic or metal candle filters. They can be used at high temperatures and pressures with the proper type of grain. In most cases, the granular materials with which it is possible to operate at high temperatures are made of ceramic such as alumina or mullite. Few data are available in the literature on the filtration efficiency of these devices. An efficiency of $99 \%$ was reported for particles with a diameter greater than $4 \mu \mathrm{m}$ and $93 \%$ for smaller particles [7, 21].

\subsection{Electrostatic precipitators}

An electrostatic precipitator (ESP) is a device that removes dust or other fine particles from gases. It comprises two electrodes between which electrical charges circulate. The discharge electrode is supplied with high voltage (negative or positive) and charges the particles present in the gas to be cleaned. Then the charged particles drift toward the earthed electrode where they are neutralized. The particles collected are recovered in the lower part of the ESP by a rapping system of the collecting electrode.

Classical ESPs are widely used in industry, especially in cement plants or incinerators, which are known to be particle-emitting activities. However, there are very few data available in the literature regarding the use of ESPs to clean gases in extreme temperature and pressure conditions. The most recent results concern the elimination of 
tars present in the synthetic gas at high temperatures $\left(200-500^{\circ} \mathrm{C}\right)$ [23-26]. Experimental studies conducted with pulsed corona discharges have shown that it is possible to remove a fraction $(0-60 \%$ of the total) of the tars contained in syngas and the ESP can convert heavy tars into lighter tars.

As for particle removal at high temperatures and pressures with an ESP, the latest scientific data date from the mid-1980s [27, 28]. According to the results obtained by Brown and Walker [29], Tassicker et al. [28] and Rinard et al. [27], it seems possible to operate with an ESP for temperatures up to $1000^{\circ} \mathrm{C}$ and pressures from 0.1 to $3.5 \mathrm{MPa}$. The temperature and pressure effects on the ESP's electrical behavior are in opposition: when the temperature increases, the ESP working zone decreases and when the pressure increases, the working zone increases as well. The ESP working zone is between the corona onset voltage and the sparkover.

We studies an electrostatic precipitator to clean the synthetic gas at high temperatures $\left(500-1000^{\circ} \mathrm{C}\right)$ because this technique offers numerous advantages over other filtration technologies, most particularly:

* There is no pressure drop due to filter clogging.

* It can collect a wide range of particle sizes $(0.01-100 \mu \mathrm{m})$ with observed filtration efficiency between 95 and $100 \%$ [28].

\section{EXPERIMENTAL APPARATUS AND METHODS}

\subsection{Experimental bench scale of Grenoble CEA}

The fluidized bed facility was designed to study biomass steam gasification up to $1000^{\circ} \mathrm{C}$ and $4 \mathrm{MPa}$. The facility is composed of a vertical part connected to a horizontal part (for biomass feeding). The internal reactor and the feeding screws are surrounded by an external vessel made of stainless steel and designed to sustain a pressure of $4 \mathrm{MPa}$. The internal reactor is heated by nine independent electric resistance heaters. The biomass conveying screw can also be heated by two heating elements.

The internal reactor is composed of a lower part, where biomass is fluidized, followed by a disengagement zone. The biomass is stored in a large pressurized bunker and is introduced into the reactor with two feeding screws (a dosing screw followed by a conveying screw with a high rotation velocity of $75 \mathrm{t} . \mathrm{min}^{-1}$ ). The feeding rate lies within the $0.2-5 \mathrm{~kg} \cdot \mathrm{h}^{-1}$ range. Argon is injected into the bunker and along the conveying screw to avoid syngas flowback.

The fluidizing gas is steam or a mixture of steam and nitrogen. The gas distributor is a plate supplied with 12 nozzles with four holes ( $1 \mathrm{~mm}$ in diameter) on each of them.

Output gas flows through metallic high-temperature filters, where particulates are removed, before leaving the reactor. These filters are made of Hastelloy® (Haynes International), a nickel-based alloy, and are designed to stop $99.9 \%$ of the particles under $0.5 \mu \mathrm{m}$. The gas temperature is maintained at $600^{\circ} \mathrm{C}$ until it flows through three successive cold traps, where water and tars are condensed. These heat exchangers are cooled to $15^{\circ} \mathrm{C}, 0^{\circ} \mathrm{C}$ and $20^{\circ} \mathrm{C}$, respectively. The total mass flow rate of the dry exit gas on this line is measured with a Coriolis mass flow meter. To carry out the syngas filtration tests with an electrostatic precipitator, these metallic filters were removed from the gasifier. Figure 2 shows the downstream implementation of the HTFB (High Temperature Fluidized Bed), in particularly the ESP location.

The syngas arrives at the bottom of the ESP at a temperature between 600 and $850^{\circ} \mathrm{C}$ and a pressure of $0.2 \mathrm{MPa}$. The ESP, used for conducting the filtration tests, is made of an outer A310 steel cylinder (AFNOR norm Z12CNS 25/20) (20 mm in diameter, $270 \mathrm{~mm}$ in length), insulated to minimize heat loss and a central discharge electrode wire in A309 steel (0.4 mm in diameter) (AFNOR norm Z12CNS 25/13) (Fig. 3). It was vertically placed and supplied with a high negative voltage. It is connected to a high-voltage power supply TECHNIX® (SR-10-N-300, $10 \mathrm{~mA}-10 \mathrm{kV}$ ), which is driven at a constant current. It was chosen to work with the ESP at a negative voltage due to the results obtained by various authors who have studied the ESP's electrical behavior at high temperatures and pressures [27-29]. These authors specified that the ESPs are more stable and obtain better filtration efficiency at high temperatures and pressures under negative voltage. The electrostatic precipitator is maintained at the working temperature with a heating tape insulated quartz braided fiber and controlled via a temperature controller coupled to a type $\mathrm{K}$ thermocouple. A counter-current heat exchanger was placed before the particle collection tank in order to keep it at room temperature.

The particles removed from the syngas are initially collected on the surface of the collected electrode, where they form a cake, then unclogged sequentially by application of a pressure difference associated with a striking system of the collected electrode. This requires creating a vacuum inside the recovery tank using a vacuum pump by opening the VAF4 valve (Fig. 2). Once the vacuum is created, the VAF4 valve is closed and the VAF3 valve is opened suddenly, causing a pressure drop in the ESP; then the particles are entrained into the recovery tank placed at the bottom of the ESP.

The purified gas is directed toward the cold trap (PG1) in which water and tars contained in the syngas are trapped by condensation. Some of the particles, which have not been stopped by the ESP, are trapped in the cold 
trap. Then the syngas passes through a high-efficiency particle filter (1), which removes the remaining particles in order to avoid clogging the facility's measurement and analysis instruments. The dry gas flow is given by the quantum flow system (QFS) flow control. The gas composition is analyzed in real time with a gas chromatograph $(\mu \mathrm{GC})$. The tars and the presence of ammonia or hydrogen cyanide are measured through a bubbling system.

The flow of particles in the raw syngas is determined by passive sampling, which is mandatory to be able take measurements at high temperatures. To date there is no particle sizer available on the market that can operate at high temperatures $\left(>200^{\circ} \mathrm{C}\right)$. Their use requires cooling the aerosol before it is analyzed, which can skew the data; during cooling, the aerosol can be modified (formation of agglomerates, condensation, etc.). To measure filtration efficiency of the electrostatic precipitator, a syngas fraction is diverted to the high-efficiency particle filter (2); then it passes through a flow meter to determine the exact volume of filtered gas. By gravimetric measurement of the high-efficiency particle filter with a known filtered gas volume, it is possible to determine the particle flow entering the ESP. The recovery tank is weighed before and after each filtration test to determine the particle mass collected by the ESP. To know the incoming particle mass and the mass of the particles collected allows one to calculate the mean filtration efficiency.

We chose to conduct the syngas filtration tests at a set discharge current $(I=0.5 \mathrm{~mA})$ and to follow the potential difference variation $(\mathrm{V})$ over time. Two filtration tests were conducted: the first at a temperature of $510^{\circ} \mathrm{C}$ and the second at $680^{\circ} \mathrm{C}$. Table 2 summarizes the experimental conditions of each of these tests.

\subsection{Biomass feedstock composition}

The biomass used for syngas filtration tests at high temperatures is a mixture of perfectly calibrated spruce sawdust (1.2-2.8 mm), type S12, provided by SPPS (www.sppsfrance.com). Table 3 gives the composition of this biomass.

\subsection{Syngas composition produced}

The syngas composition and flow rate produced by the HTFB are measured in real time. The changes in the syngas composition for each filtration test are given in figures 4 and 5. Overall, the syngas composition remains relatively constant throughout the experiment. During the filtration test conducted at $\mathrm{T}=680^{\circ} \mathrm{C}$, there was a problem with the biomass supply because of the presence of two peaks in figure 5. The biomass supply mechanism and the pressure inside the HTFB formed a biomass plug that, once ejected, resulted in a substantial increase in the biomass injection in the gasifier in a very short period of time. The volume of gas produced depends directly on the biomass flow introduced and a sudden increase in syngas production was observed.

The composition of the gas after the gas chromatographic analysis corresponds to dry gas, whereas the gas that passes through the ESP contains water vapor. The steam is injected in excess to allow biomass steam gasification; then it is removed downstream of the ESP by cold traps. Thus, the steam is not taken into account when the syngas is analyzed. The dry gas composition is known, the water volume initially introduced as well as the gas trapped, making it possible to determine the composition of the wet gas purified by the ESP. Table 4 gives the average composition of dry gas and wet gas from the HTFB.

\subsection{Technical problems}

When the gas temperature increases, an abnormal potential difference drop at the ESP terminal is observed. To highlight the problem, a function test of the ESP was conducted with air by gradually increasing the temperature of the process. Figure 6 compares the experimental corona onset voltage values with those calculated via the Peek formula (Eq. 1) [30-33] as a function of gas temperature. This equation allows determining the minimum potential difference value necessary to apply at the ESP as a function of the geometry of the latter to ionize a gas. Equation 1 is given for wire-cylinder geometry.

$$
V_{0}=3.1 \cdot 10^{6} \cdot \delta \cdot f \cdot\left(1+\frac{0.0308}{\sqrt{\delta \cdot R_{0}}}\right) \cdot R_{0} \cdot \ln \left(\frac{R}{R_{0}}\right)
$$

with $\delta=\frac{\mathrm{M}_{\text {gas }}}{\mathrm{M}_{\text {air }}} \frac{\mathrm{P} \cdot \mathrm{T}_{0}}{\mathrm{P}_{0} \cdot \mathrm{T}}: T_{0}$ and $P_{0}$ are taken in the standard conditions $\left(T_{0}=298 \mathrm{~K}\right.$ and $\left.P_{0}=101325 \mathrm{~Pa}\right)$ [30], $R_{0}$ is the wire radius and $R$ is the wire-cylinder distance. Here $f$ is the roughness factor, which takes into account the 
state of the conductor surface. For rough or weathered conductors, the corona starts at lower voltages than if the conductor is perfectly smooth $(f=1)$. When the conductor is dirty, the roughness factor is usually taken between 0.5 and 0.7 [30, 34]. Roughness was measured with the wire used with pictures of the wire surface taken by 3D microscope and analyzed with calculation software. The roughness value was estimated approximately equal to 0.7 .

Figure 6 shows that for temperatures above $450^{\circ} \mathrm{C}$, the experimental values differ from those obtained by calculation. The observed experimental values are lower than the theoretical values and decrease with increasing temperature. This sudden potential difference drop results from a decrease in electrical insulation of the materials used when the gas temperature increases. Table 5 shows that the electrical resistance of the ceramics is much greater than required when the gas is at room temperature. However, when the temperature increases, the electrical resistance of ceramics decreases sharply and becomes insufficient beyond $600^{\circ} \mathrm{C}$. When the ceramics are not sufficiently electrically insulating, the current passes through the ceramics. Therefore, the current no longer flows through the central electrode, but directly from the electrical supply system to the ESP body along preferential paths. The current flows preferentially where the distance between the electrical supply system and the ESP body is the shortest. The shorter the distance is between the electrodes, the lower the potential difference value is for the same value of current.

The filtration tests were conducted with the ceramic having the best electrical insulation, namely alumina C799 provided by Sceram (www.sceram.com). To solve this problem, a tight passage could be used to replace the ceramic used for electrical insulation.

\section{RESULTS AND DISCUSSION}

\subsection{Filtration efficiency}

At the temperatures at which the filtration tests were done, only the average mass filtration efficiency of the ESP could be determined. Therefore, an initial weigh-in and a final of the recovery tank and the high-efficiency particle filters were conducted for each filtration test. The mass filtration efficiency of the ESP is defined as the ratio between the trapped particle mass and the mass present in the syngas from the HTFB (Eq.2).

$$
\text { Mass filtration efficiency }=\frac{\text { collected particle flow }}{\text { particle flow inthe syngas }}
$$

The average mass filtration efficiency obtained for each test was greater than $95 \%$ :

* At $\mathrm{T}=510^{\circ} \mathrm{C}$, the mass filtration efficiency was equal at $100 \%$ for a relative error of $9 \%$

* At T $=680^{\circ} \mathrm{C}$, the mass filtration efficiency was equal at $96 \%$ for a relative error of $8 \%$

The average mass filtration efficiency was very good; nevertheless, the results obtained must be viewed with caution. During this study, only an indirect measurement was taken to determine the ESP filtration efficiency. This filtration efficiency measurement is composed of numerous intermediate steps (removing filters, weigh-in of filters and particle recovery tank, etc.), which explains the great relative error values for each test.

The filtration efficiency given in this study is an average mass filtration efficiency that does not provide the filtration efficiency variation throughout the experiment and the filtration efficiency per particle size. Therefore, it is difficult to determine whether temperature has an impact on filtration efficiency by increasing or decreasing it. To obtain more precise data on ESP filtration efficiency at high temperatures $\left(>500^{\circ} \mathrm{C}\right)$, advanced analysis technologies that could analyze hot gases at these same temperatures without cooling them would be necessary.

Because it is important to improve the filtration technologies at high temperatures to determine the type of particle contained in the syngas and its size, particle samples with the ESP were studied with a scanning electron microscope (SEM). This analysis only provides the order of magnitude of the particle features.

\subsection{Qualitative study of particles collected}

The particles collected by the ESP during the filtration tests were observed with the SEM. The results from this qualitative study were compared with the experimental data available in the literature, although there are few such studies. Hasler et al. [2], Hindsgaul et al. [35] and especially Gustafsson et al. [6] provide data on particle 
size, concentration, appearance and the chemical composition of particles formed during biomass gasification. The biomass studied was wood pellets and the particle size was measured at ambient temperatures. This study showed that particles from biomass gasification are 75\% carbonaceous materials, the rest being inorganic ash whose composition depends mainly on the past and origin of the biomass. Regarding the size distribution, we reached the same conclusions as these authors, namely that it is possible to classify the particles contained in the syngas into two categories:

* The "large" particles varying in size between 1 and $100 \mu \mathrm{m}$, with a median diameter around $10 \mu \mathrm{m}$. These particles have an irregular shape (Figs. 7 and 8) and are mainly formed by the fragmentation of organic and inorganic materials.

* The "fine" particles of submicron size are mainly composed of soot. These particles are very round and fluffy in appearance (Figs. 9 and 10).

Figure 8 shows a particle composed of channels that are parallel with each other. This is characteristic of a wood particle: these are tracheids, also called fibers in the papermaking industry.

Figures 9 and 10 show that soot particles tend to agglomerate together to form larger entities.

A qualitative study of the composition of the particle collected by the ESP was carried out using the SEM. Table 6 gives the composition of two samples collected at $510^{\circ} \mathrm{C}$ and $680^{\circ} \mathrm{C}$. The compounds found in these samples are also present in the original biomass (Table 3). A significant mass fraction of silicon was observed in the particle samples collected, it comes partly from fragments of the HTFB materials. As shown in table 6, carbon is the main particle component contained in the syngas. This material has the characteristic of being easily loaded with the electrical charges generated by the ESP, which explains the high filtration efficiency obtained (> 95\%).

\subsection{Voltage value variation during the filtration test}

Figure 11 shows the variation of the potential difference at the terminals of the ESP for an intensity set at $0.5 \mathrm{~mA}$ over the filtration test performed at $510^{\circ} \mathrm{C}$. The choice to set a current value equal to $0.5 \mathrm{~mA}$ is the result of a preliminary study conducted with the ESP [36]. The aim of this previous study was to measure ESP filtration efficiency at different working current values for different aerosols. The results showed that the best filtration efficiency is obtained for a current value equal to $0.5 \mathrm{~mA}$ with this ESP. Below this value, the filtration efficiency decreases with the current value and beyond this value it is nearly identical to higher-power consumption.

The arrows in figures 11 and 12 indicate the time when the trapped particles on the collected electrode were recovered in the tank placed at the bottom of the ESP. The particles were recovered when the potential difference was too low or too unstable. After each drain, the value of the potential difference rose sharply.

During the first hour of the filtration test, particle deposit was directly formed on the ESP electrical supply system due to excessive vibrations designed to unclog the particles collected on the electrode and gather them in the tank placed at the bottom of the ESP. This particle deposition led to the formation of an electric junction hence the voltage drop observed during the first part of filtration test. After the particle deposition was removed, the potential difference value returned to its operating point between 6 and $7 \mathrm{kV}$ (average taken over the second hour of the filtration test) for a current value set at $0.5 \mathrm{~mA}$. Knowing the syngas composition and the experimental conditions set at the ESP, a theoretical working point could be determined using to the analytical model of the current-voltage curve for the wire-cylinder ESP that had been developed [37] For a current value of $0.5 \mathrm{~mA}$, the calculated potential difference is about $6.9 \mathrm{kV}$ which is very close to the experimental value.

Figure 12 gives the potential difference variation for a current set at $0.5 \mathrm{~mA}$ during the filtration test performed at $680^{\circ} \mathrm{C}$. The voltage value is very low (less than $1 \mathrm{kV}$ on average) compared with the previous filtration test. A theoretical value determined for this test should be about $6.2 \mathrm{kV}$. Taking into account what was presented in section 3.4 and table 5, this unusually low potential difference value may be attributed to the electrical insulation drop of ceramics and therefore the presence of electrical junctions through which part of the electrical current is lost. However, this phenomenon does not prevent the ESP to cleaning the syngas because during this filtration test an efficiency above $95 \%$ was observed. It is therefore necessary to improve the ESP's electrical insulation for temperatures above $500^{\circ} \mathrm{C}$ in order to optimize this technology. 
During the second filtration test, the syngas composition was disrupted twice because a biomass plug was formed (see section III.C). This change impacted the electrical behavior of the ESP as shown in figure 13. The sharp decrease in potential difference corresponds to an increase in the argon fraction and a decrease in the nitrogen fraction, the other gases evolving significantly less. Argon is a gas with no electron affinity; its presence lowers the electrical mobility of charged species and therefore induced a decrease in potential difference.

\section{CONCLUSION AND PROSPECTS}

The filtration efficiency obtained during the filtration tests conducted at the CEA site in Grenoble, FRANCE, were greater than $95 \%$ for each test. These results show that it is possible to use an ESP at temperatures above $500^{\circ} \mathrm{C}$ to remove the particles contained in syngas from biomass gasification. Taking into account the technical improvements that can be made in the filtration process, particularly as regards the electrical insulation problems, with the available technologies on the market and the different results of this study, the maximum temperature at which it seems possible to work with an ESP at the semi-industrial or industrial scale is between 700 and $800^{\circ} \mathrm{C}$. Beyond this temperature, existing technologies do not allow developing an ESP that could be operational and meet the requirements imposed by industrial production of second-generation biofuels. Caution is required with the results of filtration efficiency obtained during this study, here only an average mass filtration efficiency that raises a number of questions:

* Are all particles collected in the same way, regardless of their size and chemical composition?

* Do the particles undergo a morphological or chemical change?

* Does the filtration temperature impact particle collection by improving or lowering the particle charge? Is there an optimum filtration temperature?

Only a further study of the ESP filtration efficiency at high temperatures of syngas will answer these questions.

\section{ACKNOWLEDGMENTS}

This research was supported by the French National Research Agency and it is incorporated in the EPURGAZ project (ANR-06-BIOE-O05).

\section{REFERENCES}

[1] M.J.A. Tijmensen, A.P.C. Faaij, C.N. Hamelinck, M.R.M. van Hardeveld, Exploration of the possibilities for production of Fischer Tropsch liquids and power via biomass gasification, Biomass and Bioenergy, 23 (2002) $129-152$.

[2] P. Hasler, T. Nussbaumer, Gas cleaning for IC engine applications from fixed bed biomass gasification, Biomass and Bioenergy, 16 (1999) 385-395.

[3] R. Zanzi, K. Sjostrom, E. Bjornbom, Rapid high-temperature pyrolysis of biomass in a free-fall reactor, Fuel, 75 (1996) 545-550.

[4] I. Obernberger, T. Brunner, G. Bärnthaler, Chemical properties of solid biofuels-significance and impact, Biomass and Bioenergy, 30 (2006) 973-982.

[5] J. Han, H. Kim, The reduction and control technology of tar during biomass gasification/pyrolysis: An overview, Renewable and Sustainable Energy Reviews, 12 (2008) 397-416.

[6] E. Gustafsson, M. Strand, M. Sanati, Physical and chemical characterization of aerosol particles formed during the thermochemical conversion of wood pellets using a bubbling fluidized bed gasifier, Energy and fuels, (2007) 3660-3667.

[7] K.R. Cummer, R.C. Brown, Ancillary equipment for biomass gasification, Biomass and Bioenergy, 23 (2002) 113-128.

[8] H. Leibold, A. Hornung, H. Seifert, HTHP syngas cleaning concept of two stage biomass gasification for FT synthesis, Powder Technology, 180 (2008) 265-270.

[9] F. Muller-Langer, M. Kaltschmitt, BtL as renewable fuel - Technical-economic assessment of plant concepts, in: World Congress of Chemical Engineering, Montréal, Canada, 2009.

[10] W. Zhang, Automotive fuels from biomass via gasification, Fuel Processing Technology, 91 (2009) 866876.

[11] D. Brown, M. Gassner, T. Fuchino, F. Maréchal, Thermo-economic analysis for the optimal conceptual design of biomass gasification energy conversion systems, Applied Thermal Engineering, 29 (2009) 2137-2152.

[12] F. Seyfried, Renewable fuels for advanced powertrains, final report, in, 2008. 
[13] K. Göransson, U. Söderlind, J. He, W. Zhang, Review of syngas production via biomass DFBGs, Renewable and Sustainable Energy Reviews, In Press, Corrected Proof.

[14] R. Kramreiter, M. Url, J. Kotik, H. Hofbauer, Experimental investigation of a $125 \mathrm{~kW}$ twin-fire fixed bed gasification pilot plant and comparison to the results of a $2 \mathrm{MW}$ combined heat and power plant (CHP), Fuel Processing Technology, 89 (2008) 90-102.

[15] S.V.B.V. Paasen, L.P.L.M. Rabou, R. Bar, Tar removal with a wet electrostatic precipitator (ESP); a parametric study, in: The 2nd world conference and technology exhibition on biomass for energy, industry and climate protection, Rome, Italy, 2004.

[16] M.E. Dry, The Fischer-Tropsch process: 1950-2000, Catalysis Today, 71 (2002) 227-241.

[17] S. Rapagnà, K. Gallucci, M. Di Marcello, M. Matt, M. Nacken, S. Heidenreich, P.U. Foscolo, Gas cleaning, gas conditioning and tar abatement by means of a catalytic filter candle in a biomass fluidized-bed gasifier, Bioresource Technology, 101 (2010) 7123-7130.

[18] R. Dumon, R. Joffre, Dépoussiéreurs industriels, Masson, Paris, 1984.

[19] W. de Jong, Ö. Ünal, J. Andries, K.R.G. Hein, H. Spliethoff, Biomass and fossil fuel conversion by pressurised fluidised bed gasification using hot gas ceramic filters as gas cleaning, Biomass and Bioenergy, 25 (2003) 59-83.

[20] P. Hofmann, K.D. Panopoulos, L.E. Fryda, A. Schweiger, J.P. Ouweltjes, J. Karl, Integrating biomass gasification with solid oxide fuel cells: Effect of real product gas tars, fluctuations and particulates on Ni-GDC anode, International Journal of Hydrogen Energy, 33 (2008) 2834-2844.

[21] S.D. Sharma, M. Dolan, D. Park, L. Morpeth, A. Ilyushechkin, K. McLennan, D.J. Harris, K.V. Thambimuthu, A critical review of syngas cleaning technologies - fundamental limitations and practical problems, Powder Technology, 180 (2008) 115-121.

[22] R. Ghidossi, J.-P. Bonnet, G. Rebollar-Perez, E. Carretier, J.-H. Ferrasse, J. Vicente, F. Topin, P. Moulin, Separation of particles from hot gases using metallic foams, Journal of Materials Processing Technology, 209 (2009) 3859-3868.

[23] S.A. Nair, A.J.M. Pemen, K. Yan, F.M. Van Gompel, H.E.M. Van Leuken, E.J.M. Van Heesch, K.J. Ptasinski, A.A.H. Drinkenburg, Tar removal from biomass-derived fuel gas by pulsed corona discharges, Fuel Processing Technology, 84 (2003) 161-173.

[24] H. Tamon, H. Imanaka, N. Sano, M.O.a.W. Tanthapanichakoon, Removal of aromatic compounds in gas by electron attachment, Industrial and Engineering Chemistry research, 37 (1998) 2770-2774.

[25] S.A. Nair, K. Yan, A. Safitri, A.J.M. Pemen, E.J.M. van Heesch, K.J. Ptasinski, A.A.H. Drinkenburg, Streamer corona plasma for fuel gas cleaning: comparison of energization techniques, Journal of Electrostatics, 63 (2005) 1105-1114.

[26] S.A. Nair, K. Yan, A.J.M. Pemen, G.J.J. Winands, F.M. van Gompel, H.E.M. van Leuken, E.J.M. van Heesch, K.J. Ptasinski, A.A.H. Drinkenburg, A high-temperature pulsed corona plasma system for fuel gas cleaning, Journal of Electrostatics, 61 (2004) 117-127.

[27] G. Rinard, D.E. Rugg, T. Yamamoto, High-Temperature High-pressure Electrostatic Precipitator Electrical Characterization and Collection Efficiency, IEEE Transactions on Industry applications, 23 (1987) 114-119.

[28] O.J. Tassicker, High temperature-pressure electrostatic precipitator for electric power generation technologies: an overview of the status, Gas cleaning at high temperatures : a three-day symposium university of survey sept 1986 in institution of chemical engineers symposium series, 99 (1986) 331-349.

[29] R.F. Brown, A.B. Walker, Feasibility Demonstration of Electrostatic Precipitation at $1700^{\circ}$ F, Journal of the air pollution control association, 21 (1971) 617-620.

[30] F.W. Peek, Dielectric phenomena in High Voltage, 1929.

[31] K. Adamiak, P. Atten, Simulation of corona discharge in point-plane configuration, Journal of Electrostatics, 61 (2004) 85-98.

[32] A.M. Meroth, T. Gerber, C.D. Munz, P.L. Levin, A.J. Schwab, Numerical solution of nonstationary charge coupled problems, Journal of Electrostatics, 45 (1999) 177-198.

[33] J. Zhang, K. Adamiak, G.S.P. Castle, Numerical modeling of negative-corona discharge in oxygen under different pressures, Journal of Electrostatics, 65 (2007) 174-181.

[34] H.J. White, Industrial electrostatic precipitator, Addison - Wesley Pub. Co., 1963.

[35] C. Hindsgaul, J. Schramm, L. Gratz, U. Henriksen, J. Dall Bentzen, Physical and chemical characterization of particles in producer gas from wood chips, Bioresource Technology, 73 (2000) 147-155.

[36] A. Villot, Filtration par électro-précipitation des gaz issus de la gazéification de la biomasse à haute température $\left(300-1000^{\circ} \mathrm{C}\right)$, in: Génie des Procédés, University of Chambéry, Chambéry, 2010.

[37] A. Villot, Y. Gonthier, E. Gonze, A. Bernis, Numerical model of voltage-current curve for the wire-cylinder electrostatic precipitator $\mathrm{s}$ in negative voltage in the presence of non polar gases, IEEE Transactions on plasma science, 38 (2010) 2031-2040. 
Table 1

\begin{tabular}{|c|c|}
\hline Contaminants & Specifications (ppb) \\
\hline Sulfur & 10 \\
\hline Halogenous & 10 \\
\hline Nitrogen & 20 \\
\hline Particles & 0 \\
\hline Alkali & 10 \\
\hline $\mathrm{Cl}(\mathrm{HCl})$ & 10 \\
\hline $\mathrm{Pb}$ and $\mathrm{Cu}$ & unknown \\
\hline Tars & 0 \\
\hline
\end{tabular}

$\mathrm{ppb}$ : number of pollutants, mole per mole, of gas produced 
Table 2

\begin{tabular}{|c|c|c|}
\hline & Trial 1 & Trial 2 \\
\hline Gas flow $\left(\mathrm{m}^{3} \cdot \mathrm{h}^{-1}\right)$ & 4.83 & 5.63 \\
\hline Particle flow $\left({\left.\mathrm{mg} . \mathrm{NL}^{-1}\right)}^{-1}\right.$ & 2.2 & 2 \\
\hline Trial duration $(\mathrm{h})$ & $2 \mathrm{~h} 10$ & $2 \mathrm{~h} 25$ \\
\hline Temperature $\left({ }^{\circ} \mathrm{C}\right)$ & 510 & 680 \\
\hline Pressure $(\mathrm{MPa})$ & 0.2 & 0.2 \\
\hline Transit time $(\mathrm{s})$ & 0.063 & 0.054 \\
\hline Transit velocity $\left(\mathrm{m} . \mathrm{s}^{-1}\right)$ & 4.27 & 4.97 \\
\hline Mean current $(\mathrm{mA})$ & 0.48 & 0.54 \\
\hline Expended energy $\left(\mathrm{Wh} . \mathrm{m}^{-3}\right.$ of gas) & 0.65 & 0.07 \\
\hline
\end{tabular}




\begin{tabular}{|c|c|}
\hline Element & dry mass (\%) \\
\hline Carbon & 50.6 \\
\hline Hydrogen & 5.99 \\
\hline Oxygen & 42.8 \\
\hline
\end{tabular}

Rate of ashes at

$\mathrm{T}=550{ }^{\circ} \mathrm{C}: 0.40 \%$

\begin{tabular}{|c|c|c|c|}
\hline Element & ppm & Element & ppm \\
\hline Nitrogen & 1400 & Boron & 27 \\
\hline Calcium & 4900 & Copper & 3.2 \\
\hline Potassium & 750 & Selenium & - \\
\hline Sulfur & 340 & Lead & $<0.5$ \\
\hline Magnesium & 210 & Arsenic & $<0.1$ \\
\hline Manganese & 100 & Antimony & - \\
\hline Chlorine & 640 & Nickel & 11 \\
\hline Phosphorus & 70 & Molybdenum & - \\
\hline Fluorine & 31 & Chromium & 7.6 \\
\hline Sodium & 30 & Cobalt & - \\
\hline Iron & 160 & Cadmium & $<0.4$ \\
\hline Aluminum & 120 & Vanadium & - \\
\hline Barium & - & Tin & - \\
\hline Silicon & 120 & Mercury & $<0.05$ \\
\hline Zinc & 8 & Tellurium & - \\
\hline Silver & - & lodine & - \\
\hline Strontium & - & Bromine & - \\
\hline Titanium & 3 & Water & $12.7 \%$ \\
\hline
\end{tabular}

ppm: mass of the element per unit mass of biomass 


\begin{tabular}{|c|c|c|}
\cline { 2 - 3 } \multicolumn{1}{c|}{} & \multicolumn{2}{c|}{ Mole fraction (\%) } \\
\hline Symbol & Dry gas & Wet gas \\
\hline $\mathrm{H}_{2}$ & 17.21 & 8.6 \\
\hline $\mathrm{CO}$ & 5.51 & 2.7 \\
\hline $\mathrm{CO}_{2}$ & 7.37 & 3.7 \\
\hline $\mathrm{CH}_{4}$ & 1.98 & 1 \\
\hline $\mathrm{H}_{2} \mathrm{O}$ & - & 50.2 \\
\hline $\mathrm{N}_{2}$ & 50.96 & 25.4 \\
\hline $\mathrm{Ar}$ & 15.95 & 7.9 \\
\hline $\mathrm{C}_{\mathrm{x}} \mathrm{H}_{\mathrm{y}}$ & 0.03 & traces \\
\hline $\mathrm{H}_{2} \mathrm{~S}$ & traces & traces \\
\hline $\mathrm{COS}$ & traces & traces \\
\hline
\end{tabular}


Table 5

\begin{tabular}{|c|c|c|c|}
\hline & Mullite C610 & Alumina C799 & $\begin{array}{c}\text { Resistance needed for a fixed } \\
\text { current at } \mathrm{I}=0.5 \mathrm{~mA}\end{array}$ \\
\hline Resistance at $\mathrm{T}=25^{\circ} \mathrm{C}(\mathrm{M} \Omega)$ & 184380 & 2322900 & 12 \\
\hline Resistance at $\mathrm{T}=600^{\circ} \mathrm{C}(\mathrm{M} \Omega)$ & 0.02 & 2.32 & 14 \\
\hline
\end{tabular}




\begin{tabular}{|c|c|c|}
\hline Element & $\mathbf{T}=\mathbf{5 1 0} \mathbf{C}^{\circ}$ & $\mathbf{T}=\mathbf{6 8 0}^{\circ} \mathbf{C}$ \\
\hline Carbon & 62.9 & 68.8 \\
\hline Oxygen & 6.7 & 4.3 \\
\hline Sodium & 0.1 & 0.1 \\
\hline Magnesium & 0.6 & 0.5 \\
\hline Aluminium & 1.7 & 1.9 \\
\hline Silicon & 5.2 & 3.8 \\
\hline Phosphorus & 1.3 & - \\
\hline Potassium & 1.0 & 0.8 \\
\hline Calcium & 5.8 & 2.4 \\
\hline Titanium & 0.2 & 3.8 \\
\hline Manganese & 0.6 & 0.3 \\
\hline Iron & 1.1 & 0.4 \\
\hline Chlorine & 0.1 & - \\
\hline Nickel & 0.4 & 0.4 \\
\hline Sulfur & - & - \\
\hline Fluorine & - & - \\
\hline Zinc & - & 0.2 \\
\hline Boron & - & - \\
\hline Copper & - & - \\
\hline Chromium & - & - \\
\hline
\end{tabular}


Table 1. Maximum allowable concentrations of contaminants in the Fischer Tropsch process $[1,7,8]$

Table 2. Summary of experimental conditions of the filtration tests performed

Table 3. Composition of the biomass used

Table 4. Average composition over the filtration tests of dry gas and wet gas coming from the HTFB

Table 5. Comparison between the electrical resistance of two ceramics with that required for the ESP

Table 6. Composition of particle collected with the ESP at $510^{\circ} \mathrm{C}$ and $680^{\circ} \mathrm{C}$. This is a qualitative analysis; the quantities are given in mass fraction $(\%)$ and must be viewed as an order of magnitude 
Biomass pre-treatment: - grinding

- drying
Gazéification:

- air, oxygen or water

vapor

- atmospheric or

pressurized

- direct or indirect
Gas cleaning:

- wet/cold gas cleaning

or

- dry/hot gas cleaning
Gas processing (optional):

- reforming,

$\mathrm{CH}_{4}+\mathrm{H}_{2} \mathrm{O} \Rightarrow \mathrm{H}_{2}+\mathrm{CO}$

- shift, adjusting the $\mathrm{H}_{2} / \mathrm{CO}$

ratio

$\mathrm{CO}+\mathrm{H}_{2} \mathrm{O} \Rightarrow \mathrm{CO}_{2}+\mathrm{H}_{2}$

- $\mathrm{CO}_{2}$ removal
Fischer-Tropsch synthesis:

- reactor type (slurry or fixed bed) 


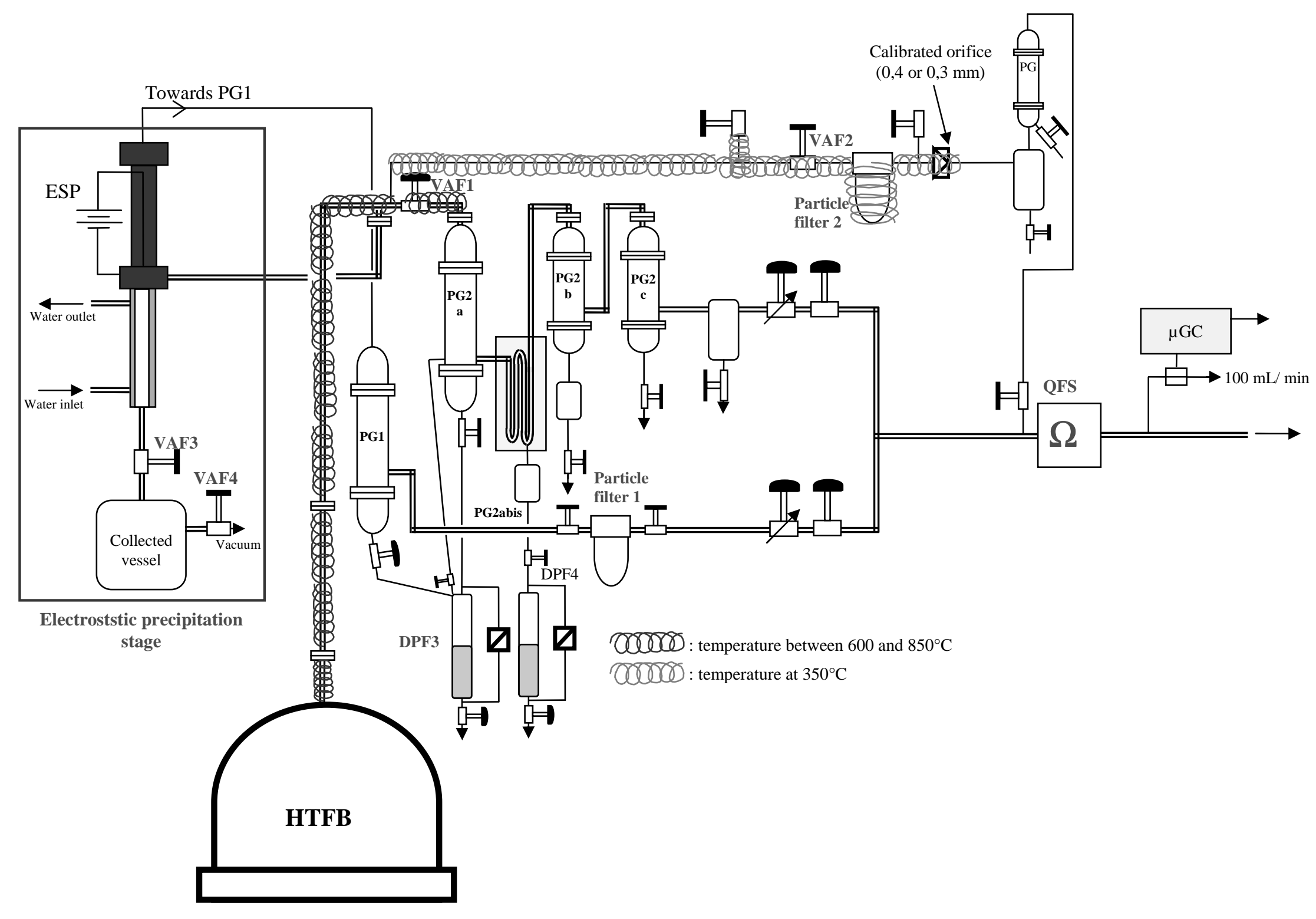


Figure 3

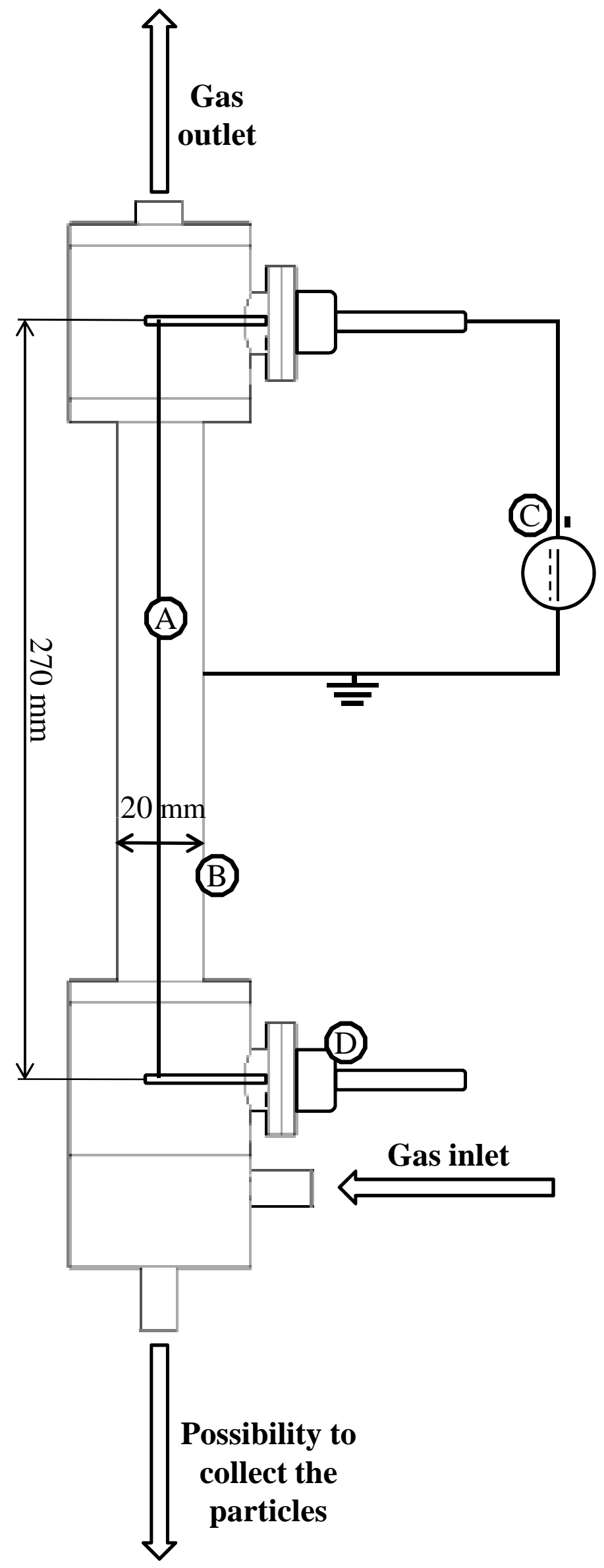




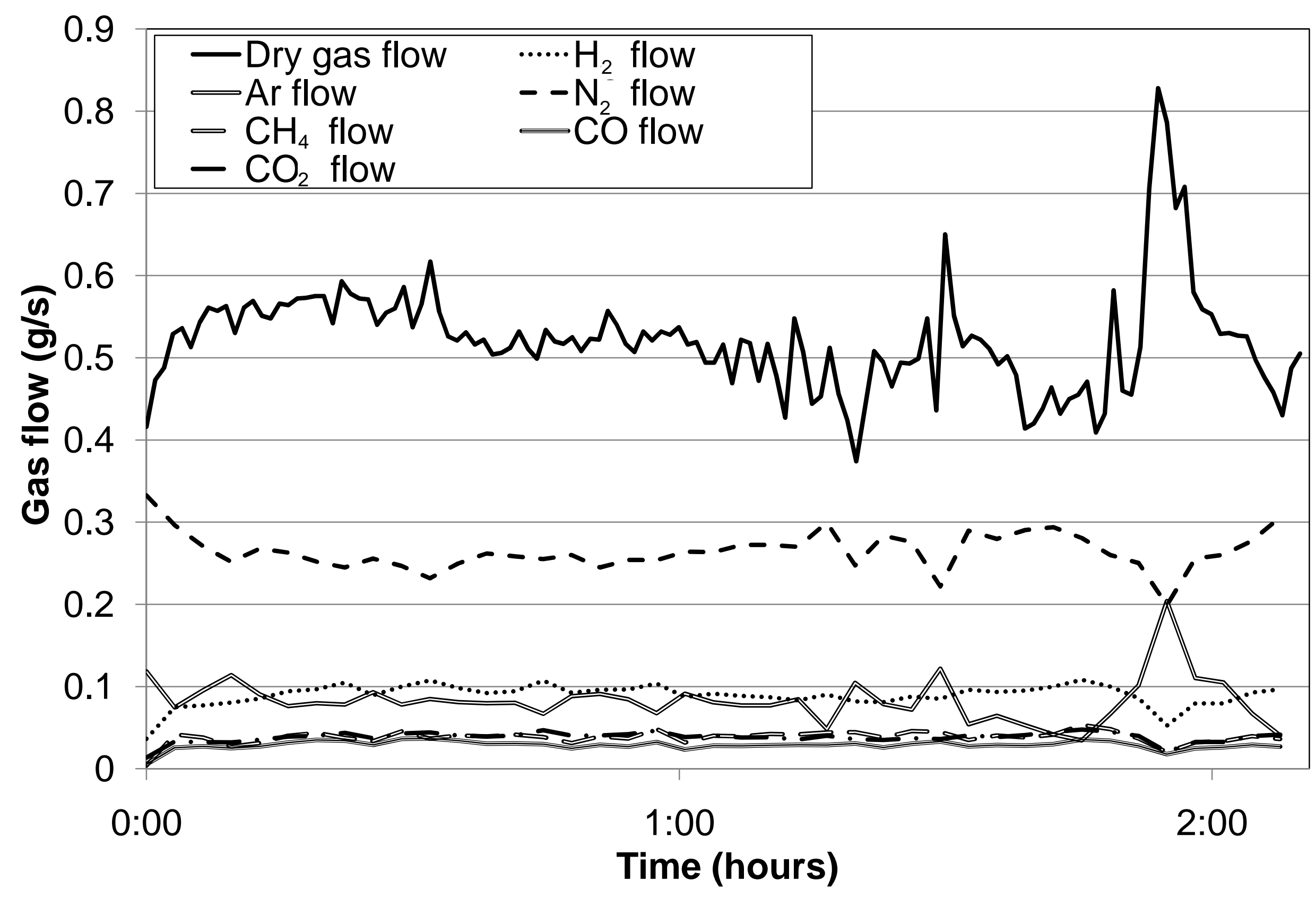




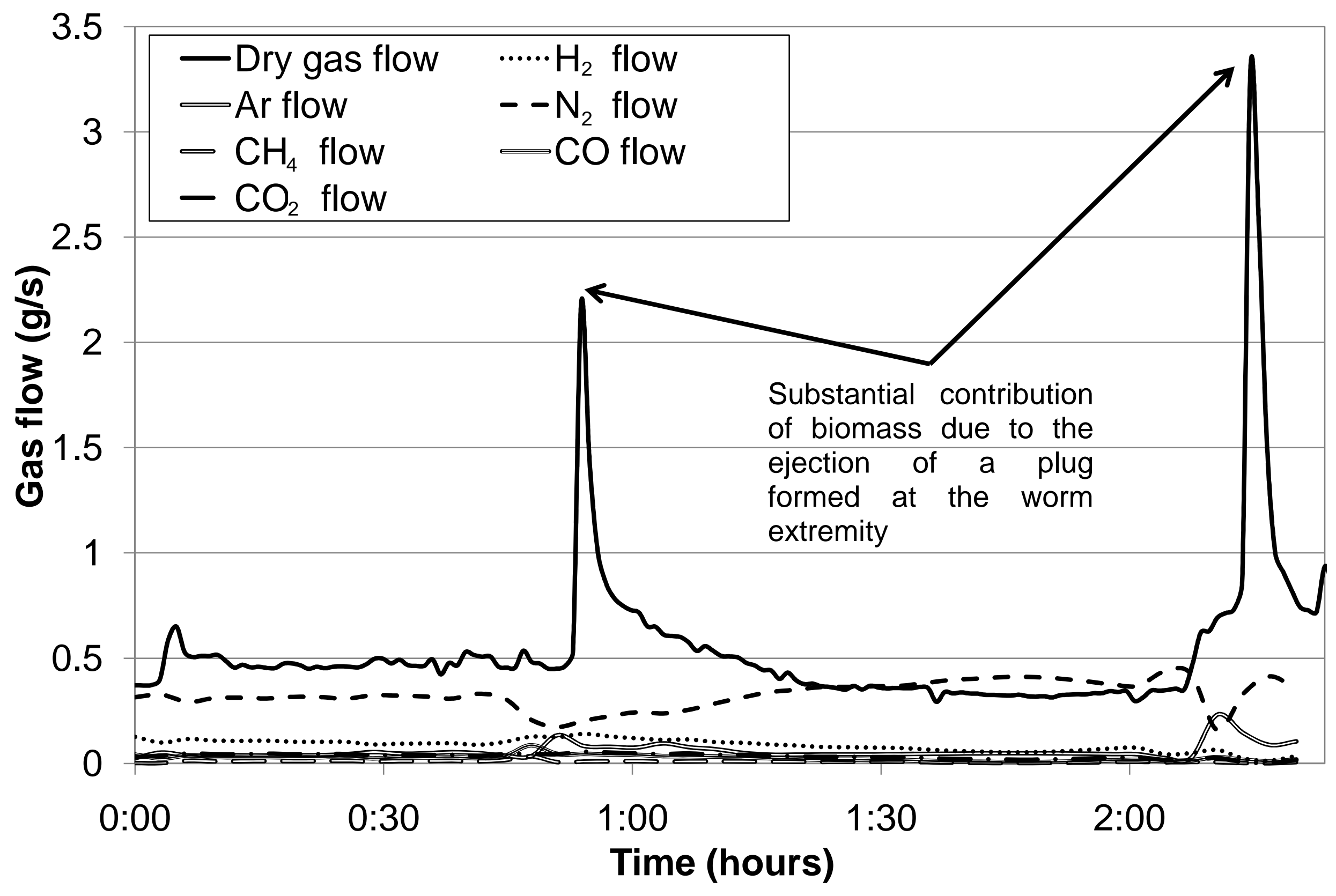




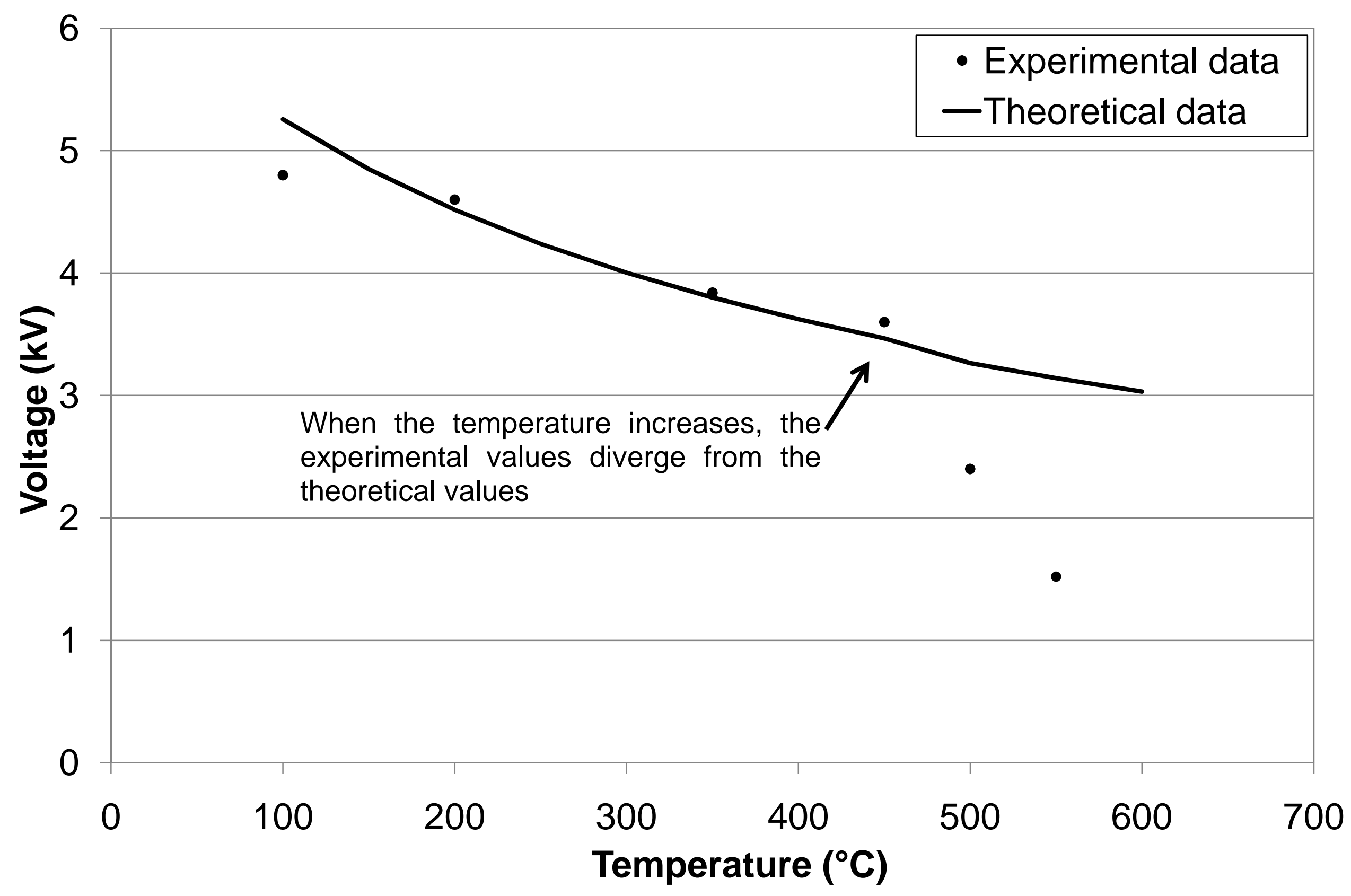




\section{Figure 7}

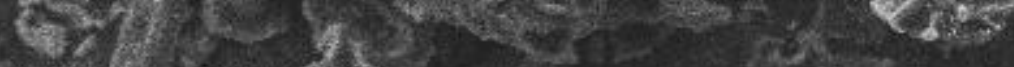

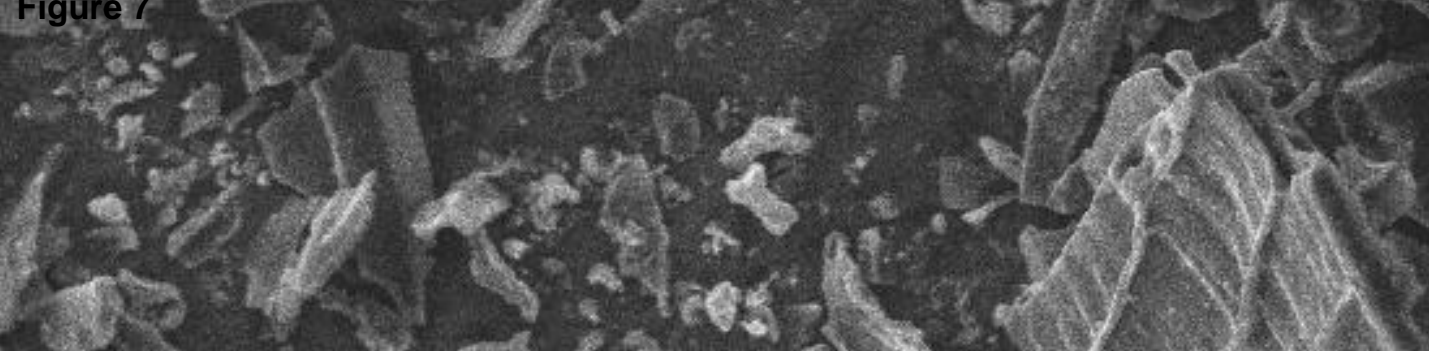

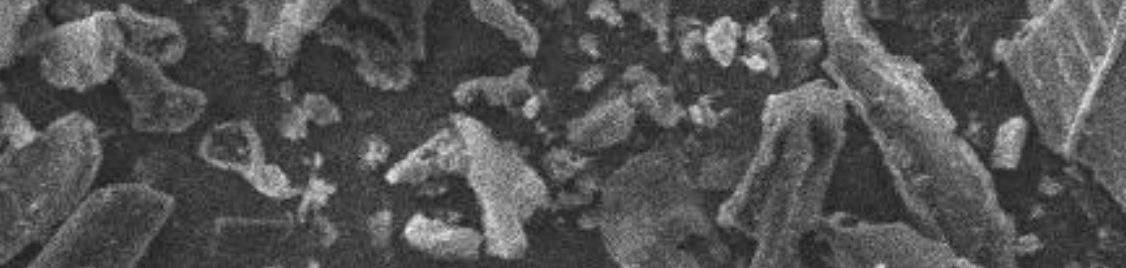

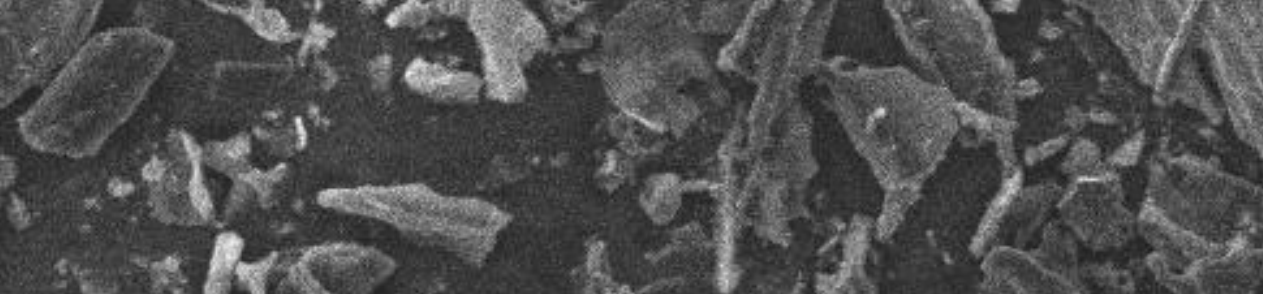
$5 \cdot 0 x^{2}=$ Q

(1). $5=$ a. a.

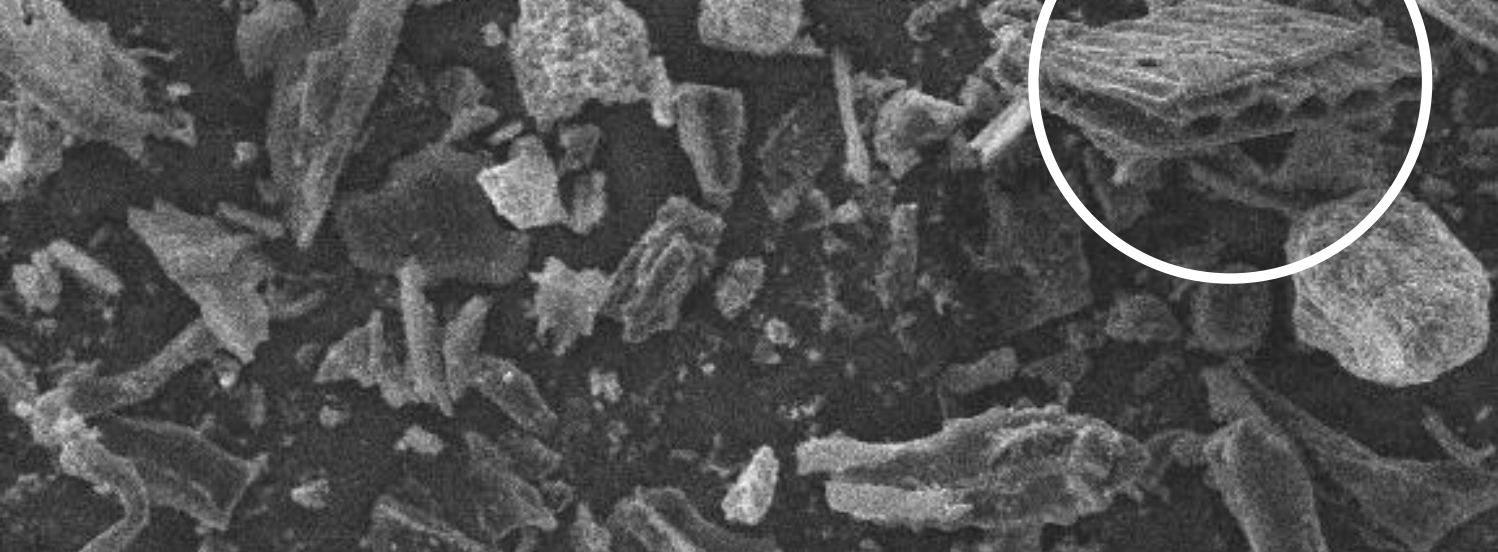

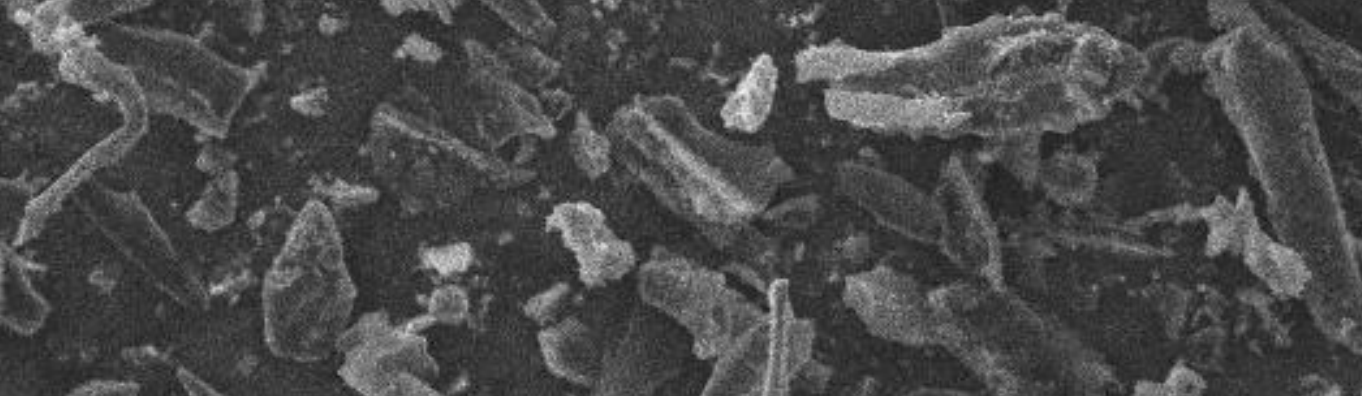

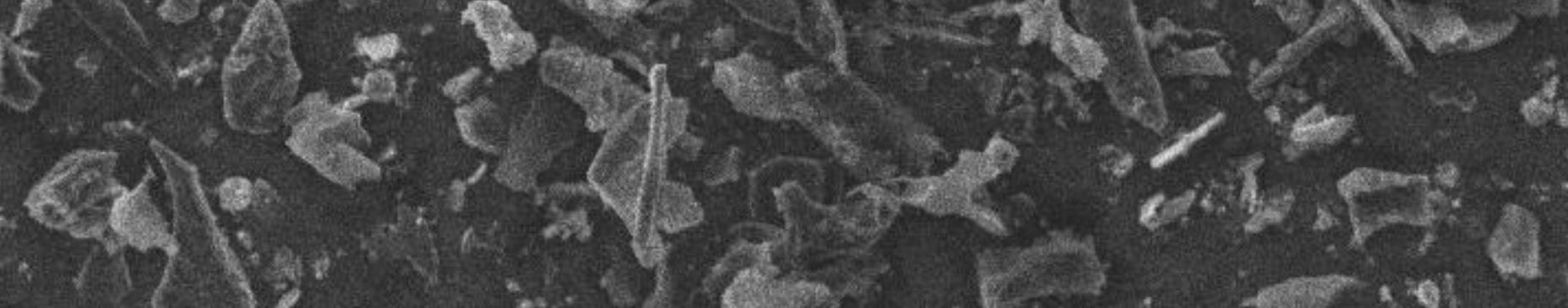

2. $x^{2}=13$

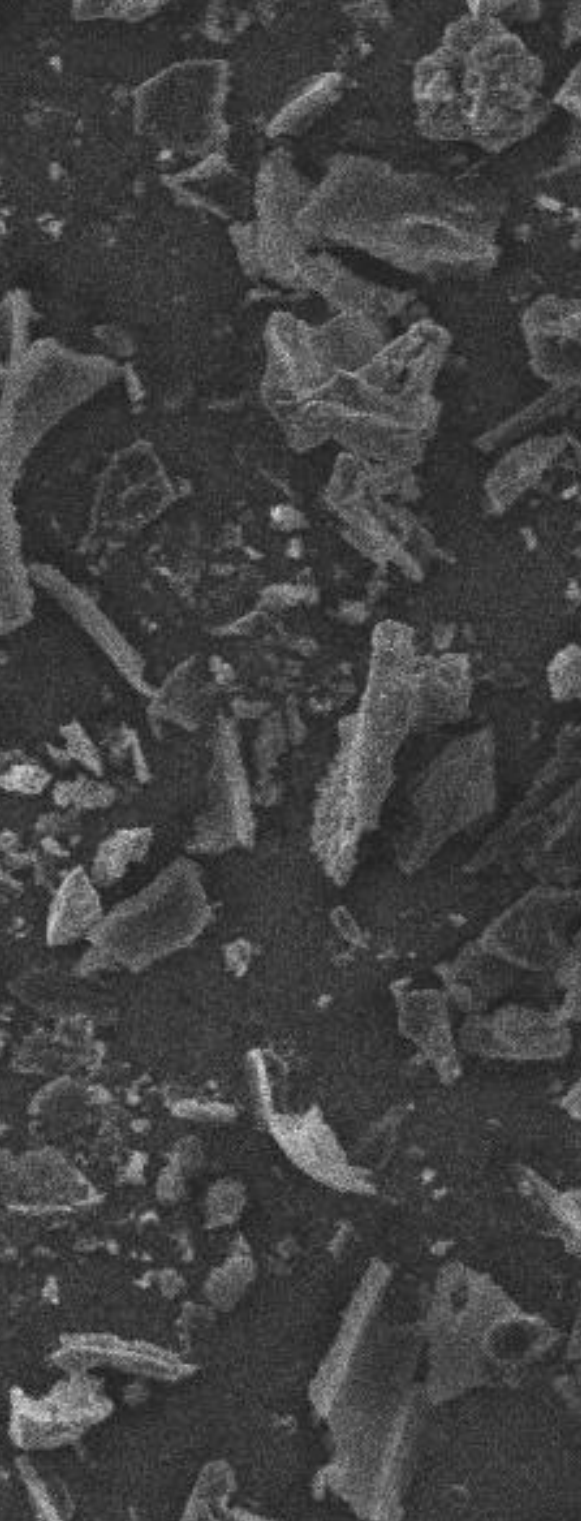

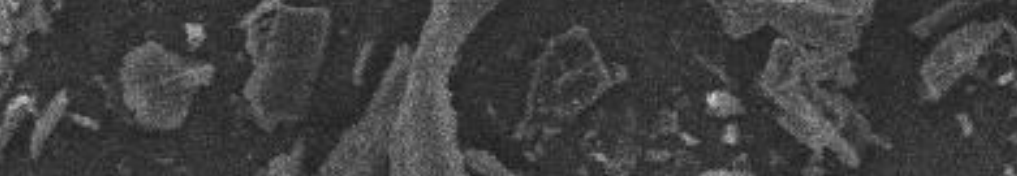
2345 $Y$

ats

$+2$ oním 


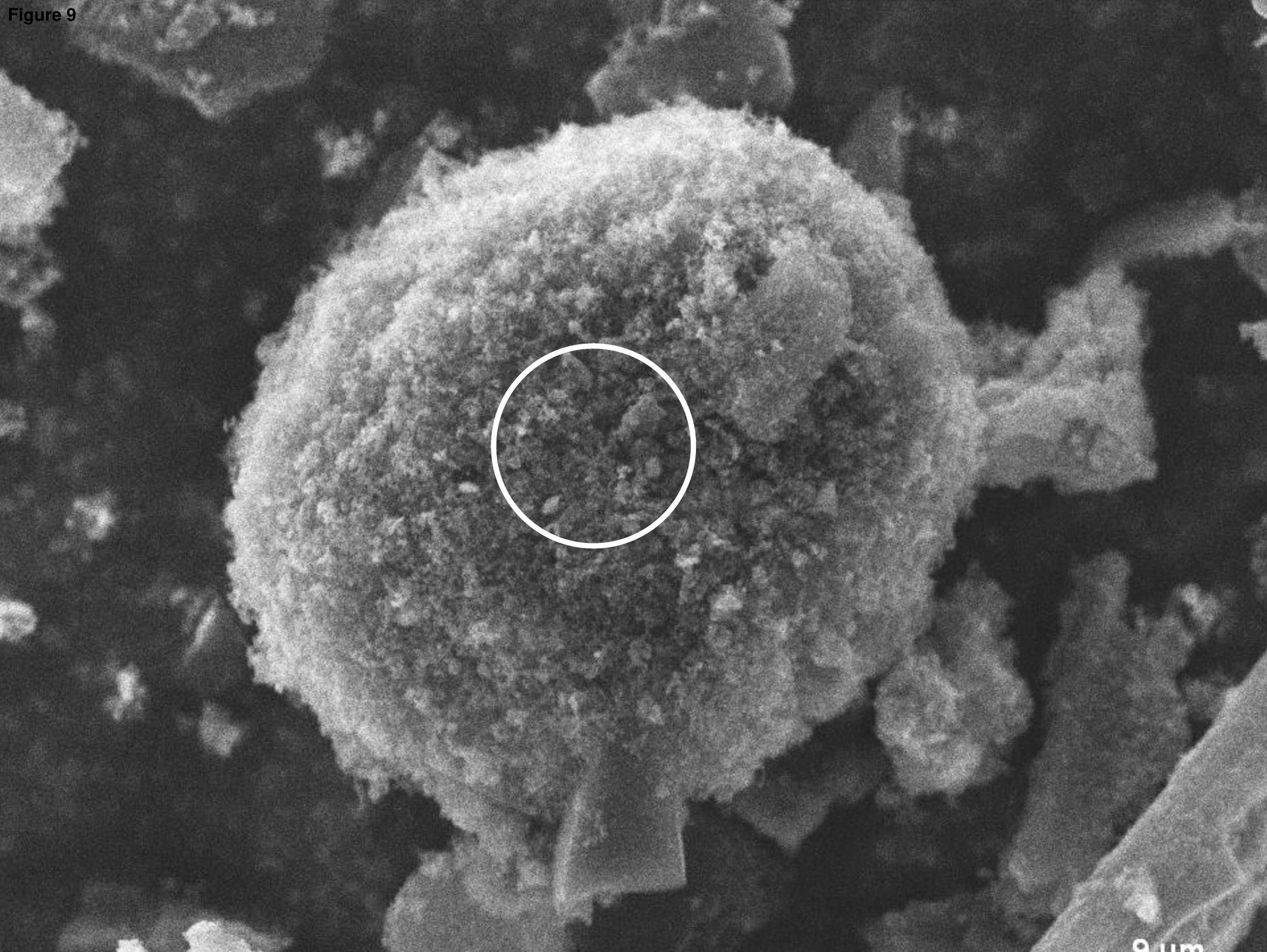




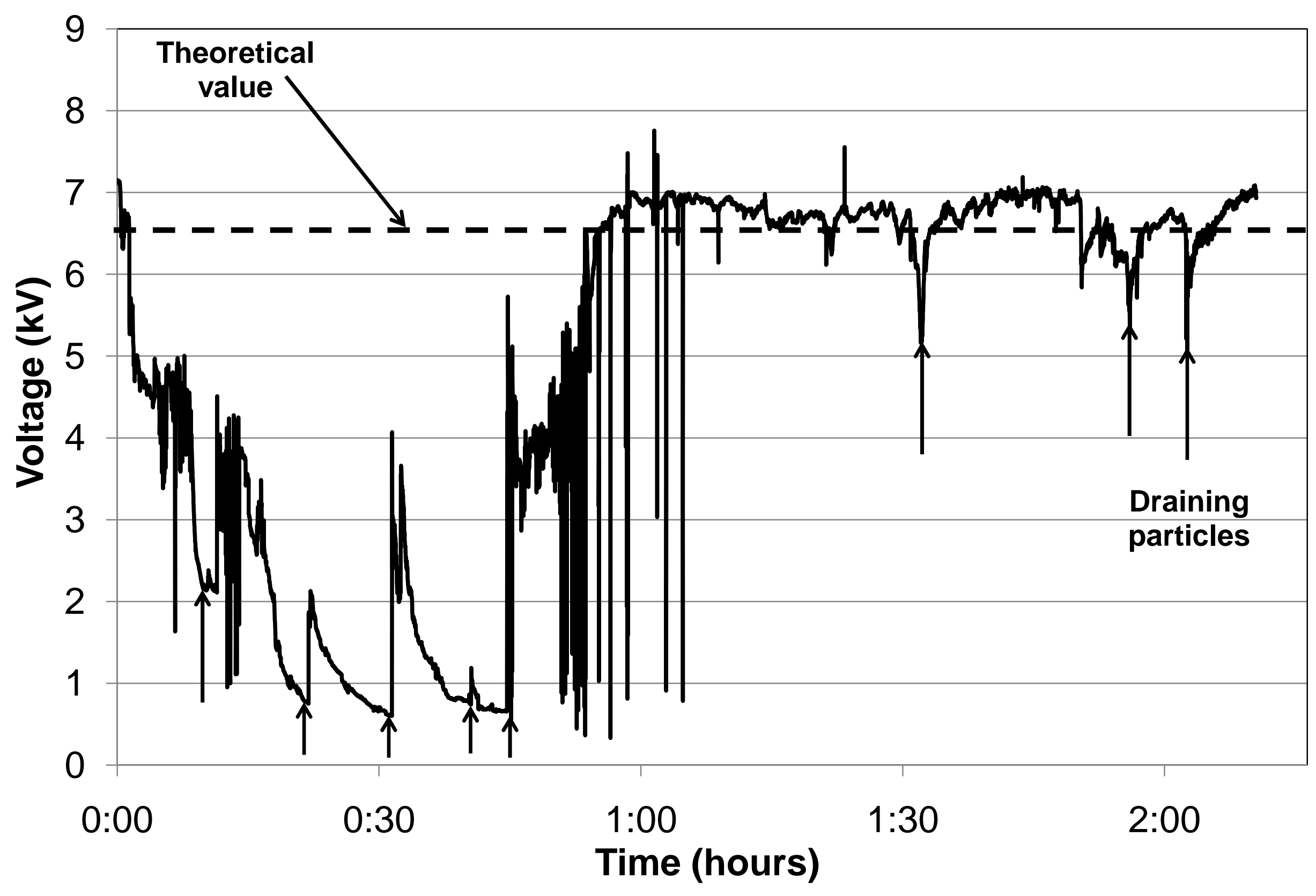




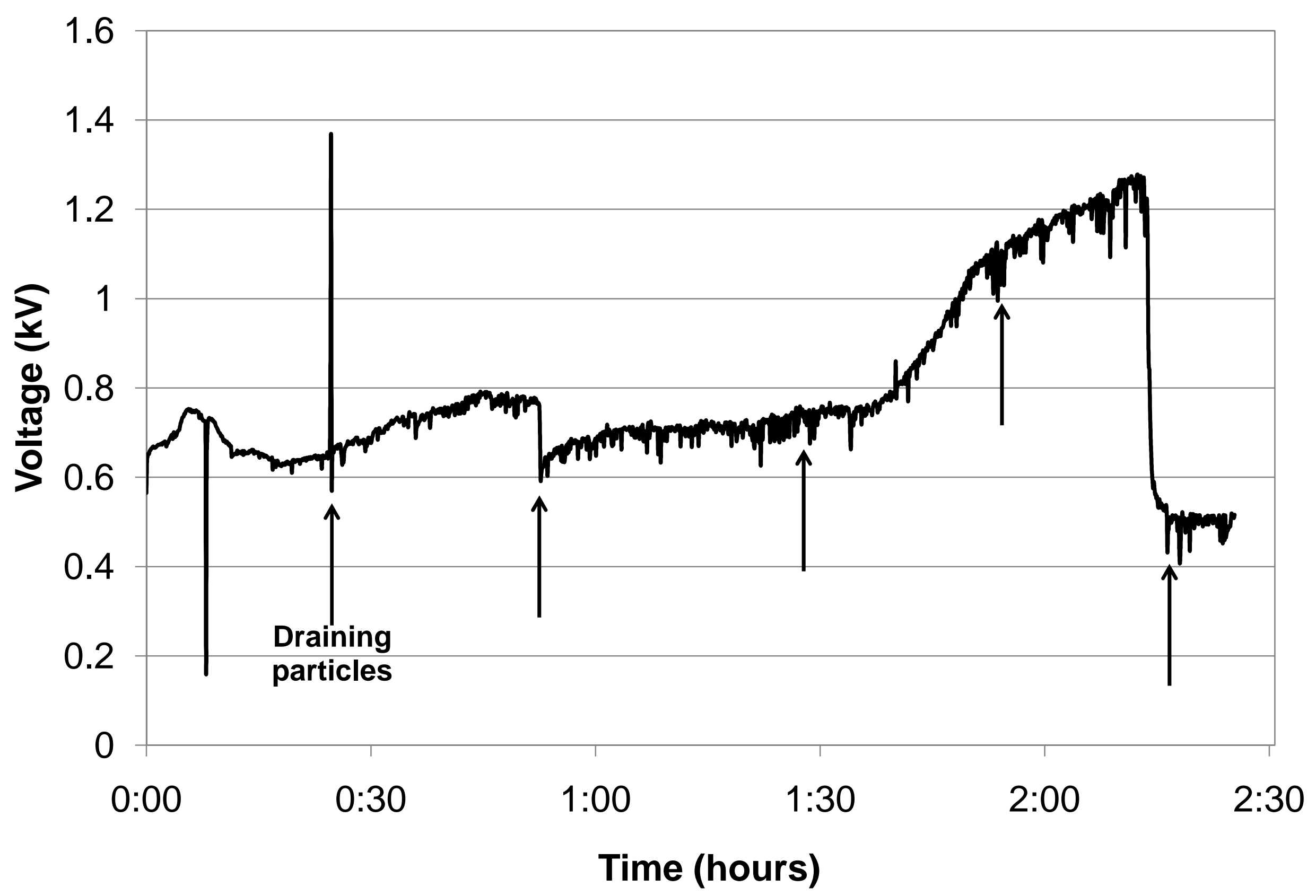




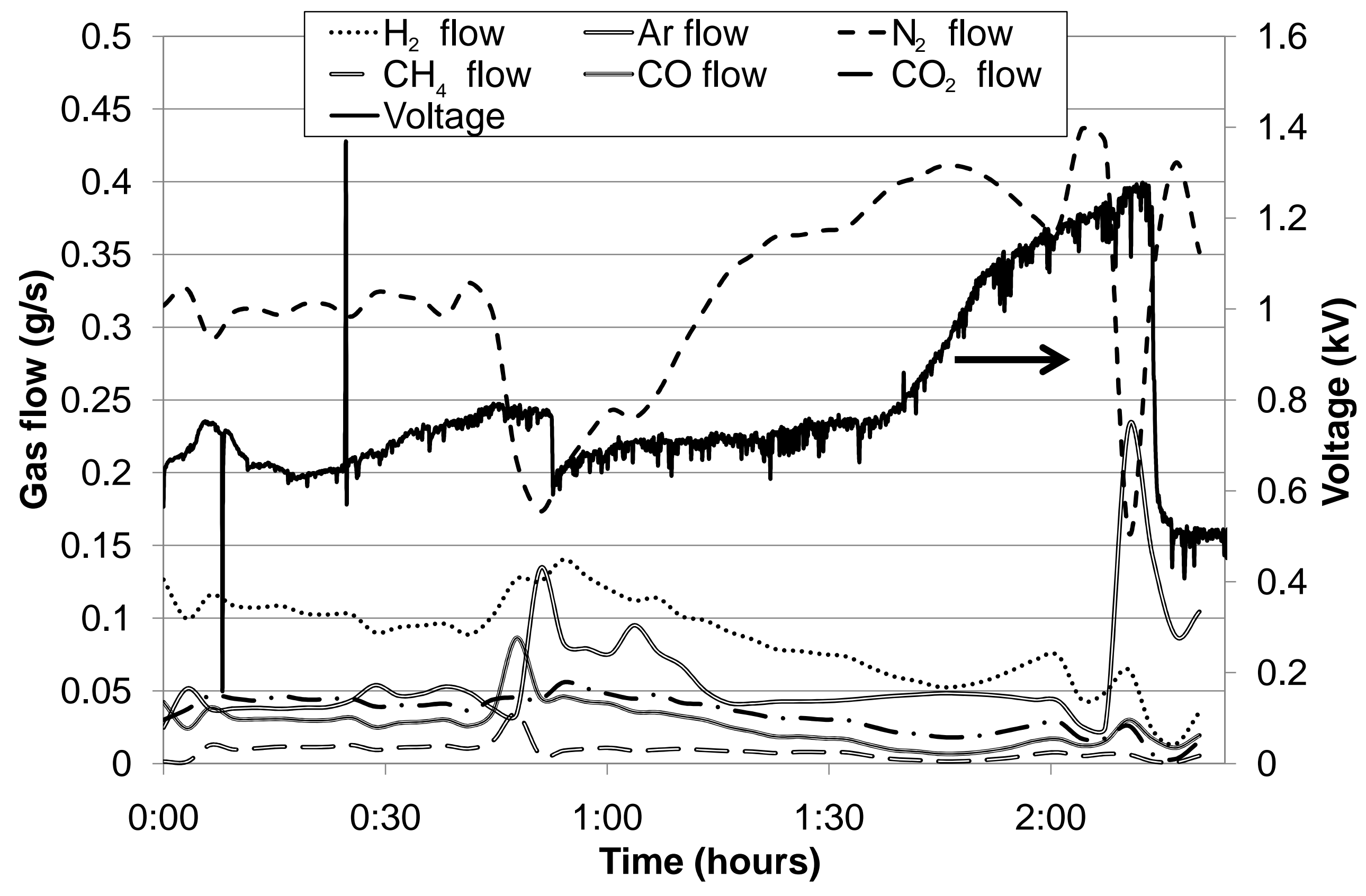


Fig. 1. Overview of biomass to Fischer-Tropsch liquid fuel

Fig. 2. Experimental bench scale biomass gasification located at the GRENOBLE CEA site (France) in which the electrostatic precipitator was placed directly downstream of the HTFB.

Fig. 3. Diagram of the wire -cylinder ESP. The central wire (A) is tightened between two electric candles for the electricity supply and the outer cylinder (B) is grounded. The power supply (C) is with a negative polarity. The electric candles are insulated with ceramic (D).

Fig. 4. Syngas composition from the HTFB for the filtration test conducted at $\mathrm{T}=510^{\circ} \mathrm{C}$ and $\mathrm{P}=0.2 \mathrm{MPa}$

Fig. 5. Syngas composition from the HTFB for the filtration test conducted at $\mathrm{T}=680^{\circ} \mathrm{C}$ and $\mathrm{P}=0.2 \mathrm{MPa}$

Fig. 6. Comparison between experimental onset voltages and those determined by calculation for air at atmospheric pressure as a function of temperature

Fig. 7. SEM image of a particle sample collected by the ESP

Fig. 8. Magnification of the area circled in figure 7

Fig. 9. Magnification of the area circled in figure 8

Fig. 10. Magnification of the area circled in figure 9

Fig. 11. Variation of potential difference value between the electrodes over the syngas filtration test conducted at $\mathrm{T}=510^{\circ} \mathrm{C}$ and $\mathrm{P}=0.2 \mathrm{MPa}$

Fig. 12. Variation of potential difference value between the electrodes over the syngas filtration test conducted at $\mathrm{T}=680^{\circ} \mathrm{C}$ and $\mathrm{P}=0.2 \mathrm{MPa}$

Fig. 13. Effect of the syngas composition on the electrical behavior of the ESP 